\title{
Sarah Kane e o mito de si: sob o guarda-chuva, com um projeto em punho à sombra do golem
}

Sarah Kane and the myth of self: under the umbrella, with a project in yours hands in the shadow of the golem

Rummenigge Medeiros de Araújo ${ }^{1}$ 


\section{Resumo}

Este artigo aborda a dramaturgia na contemporaneidade a partir da noção de escritura como sendo uma multiplicidade de espaços preenchidos por meio da performance da escrita, do projeto existencial e da presença do autor que articula e tenciona linhas de fuga para suas ideias e sentimentos. Nessa perspectiva da escrita de si, a dramaturga inglesa Sarah Kane constrói uma estrutura de sentimento orientada por três pilares; texto-corpo-mundo, imbricando vida e obra. Dessa maneira, Kane instaura uma dramaturgia cujo projeto estético é a finitude com suas diferentes noções e entendimentos de morte: diálogo com os mortos da tradição teatral e literária, morte da personagem e seu próprio suicídio.

Palavras-chave: Dramaturgia; escritura; Sarah Kane; personagem golem

\section{Abstract}

This article addresses dramaturgy in contemporaneity, using the notion of writing as a profusion of occupied spaces through the performance of the writing act, the author's presence and her existential project. Her presence articulates and tensionates the escape routes to her ideas and feelings. In such perspective of writing of oneself, british playwright Sarah Kane builds a feeling structure supported by three pillars: text-body-world, overlapping her life and work. This way, Kane establishes a dramaturgy whose aesthetical project is the finitude, with her different notions and understandings of death: the dialogue with the dead of the literary and theatrical tradition, the death of the character and her own suicide.

Keywords: Dramaturgy; writing; Sarah Kane; Golem character
ISSN: 1414.5731

E-ISSN: 2358.6958

${ }^{1}$ Prof. Dr. Instituto Federal de Educação, Ciência e Tecnologia do Rio Grande do Norte. rummaraujo@gmail.com 
Os autores Roland Barthes (2004) e Jacques Derrida (1973) apresentam entendimentos divergentes acerca das noções de escrita, literatura e escritura, porém, parecem concordar num ponto específico quando se trata da ideia de encarar e abordar a escritura como um espaço de criação em aberto no qual devem convergir e abrigar possibilidades distintas de rastros, escritas e espaçamentos. Um lugar que se debruça sobre si mesmo. Esse espaço pode também ser caracterizado pela noção que Gilles Deleuze (1998) traz acerca de um espaço desterritorializado, no qual atuam as linhas de fuga:

\begin{abstract}
A linha de fuga é uma desterritorialização. Os franceses não sabem bem do que se trata. Evidentemente, eles fogem como todo mundo, mas acham que fugir é sair do mundo, mística ou arte, ou então que é algo covarde, porque se escapa aos compromissos e às responsabilidades. Fugir não é absolutamente renunciar às ações, nada mais ativo que uma fuga. É o contrário do imaginário. É igualmente fazer fugir, não obrigatoriamente os outros, mas fazer fugir algo, fazer fugir um sistema como se arrebenta um tubo... Fugir é traçar uma linha, linhas, toda uma cartografia (Deleuze, 1998, p. 47).
\end{abstract}

As linhas de fuga permitem sair do sistema, transbordar e atravessar as formas. Seria a abertura infinita da escritura para um mundo dos possíveis, a transformação do espaço escriturário em um mundo onde todos os gêneros, estilos, escritas e possibilidades convergem, cruzam-se, deixam-se traspassar e escapam para construir outros desenhos e esquemas cartográficos possíveis. Esse espaço da multiplicidade e da heterogeneidade que configura o mundo da escritura permite (re)pensar e (re) elaborar todas as formas de escritas existentes, inclusive a escrita dramatúrgica.

Pensar a(s) escrita(s) dramatúrgica(s) na contemporaneidade é considerar principalmente a via das linhas de fuga. Pensar na congregação da heterogeneidade dos gêneros dramatúrgicos e nas possibilidades de existência do "isso e do aquilo", bem como das disjunções exclusivas de todas as ordens numa (des)orquestração de um universo particular ao dramaturgo.

Esse espaço entendido como escritura, amplamente discutido por autores importantes durante as décadas de 1970 e 1980 nas áreas do conhecimento ligadas às ciências humanas, será também um espaço reivindicado pelo teatro ao longo de um processo histórico, que, a título de exemplo, passa a ser marcadamente interrogado por Bertolt Brecht, com a sua ideia de épico, e uma geração de dramaturgos e autores absurdistas como Antonin Artaud, Alfred Jarry, Samuel Beckett, Arthur Adamov, Albert Camus, Eugene Ionesco, Harold Pinter, Heiner Müller etc. Que foram enfáticos ao retratar em suas obras a falibilidade e a morte da linguagem e, consequentemente, o silêncio e a impossibilidade de comunicação, como uma potência do homem em crise.

Ainda nesse movimento de traçar linhas de fugas, e pensando a partir do procedimento da desterritorialização das áreas de conhecimento, na configuração e na construção de outros espaços heterogêneos e heterotópicos, é que Alex Beigui (2011) vem, além de endossar a discussão dos autores já citados nesse texto, pensar a literatura e a dramaturgia pela via da performance, acrescentando assim, um outro olhar sobre a escritura, sobretudo, a escritura teatral contemporânea. 


\section{Performance e escrita: a escritura como um espaço guarda-chuva}

Beigui (2011) convida a pensar o campo da performance como um espaço "guarda-chuva", capaz de abrigar e reunir em sua copa aberta, concomitantemente, os materiais mais diversos e variados possíveis. O uso da imagem do guarda-chuva para ilustrar esse espaço acontece alusivamente ao desenho ergonômico da estrutura do objeto, que traz por baixo de sua cobertura feita de tecido ou de material impermeável, um complexo de linhas paralelas que se erguem no mesmo instante para estruturar e dar suporte a uma quantidade significativa e heterogênea de presenças distintas.

Dessa maneira, chegamos a um entendimento de que a performance é capaz de congregar e contribuir tanto para a ampliação dos horizontes teóricos e práticos das pesquisas em processos de criação (sobretudo as que envolvem linguagens de fronteira), como com os dispositivos estéticos e culturais, abrindo caminhos alternativos de escoamento e vazão para determinados sistemas que, pela exaustão do uso e pelo grau de fixação das modalidades operacionais, tendem à desordem e ao declínio. Ou ainda:

A disseminação do campo da performance exige um redimensionamento do lugar da escrita no campo das letras e da linguagem, pois na junção que estabelece entre os diversos modos de subjetivação envolvidos na prática escritural, ela evidencia os aspectos relacionais entre a escrita e a inscrição do sujeito no discurso que a produz, seja ele de natureza literária, ficcional ou crítica. Em princípio, a performance encena a natureza liminal, para usar um termo caro a Victor Turner, de uma bio-grafia, de um exercício contínuo de experimentação presentes tanto na literatura dos poetas malditos quanto na literatura pós-joyciana. Performances da escrita envolvem o "desempenho" de autoentendimento que a natureza do discurso insiste em realizar, aspecto que intensifica o ato incansável de perdurar, existir, viver-morrer através da escrita. A relação entre vida e arte pode ser comparada, na literatura, com "entrelugares": Eros e Tânatos, vida e morte, prazer e dor, cuja fisicalidade do horror de perecer se faz carne e se faz verbo no corpo, sempre corpo, do texto (Beigui, 2011, p.28).

Dessa maneira, o texto da escritura é o espaço ou o conjunto de espaços que ela engendra e articula no seu interior. O espaço da escritura, assim como o da vida, é um espaço heterogêneo por natureza. No dia-a-dia, ocupamos e nos deslocamos por diferentes níveis e estruturas espaciais, organizando a vida social e as relações interpessoais em função desses espaços que não se sobrepõem, mas existem em paralelo e em simultâneo criando um espaço maior no qual acontece a vida.

Nessa perspectiva, a escritura performática une e imbrica vida e obra, de maneira a borrar por completo as fronteiras entre a ficção, a não ficção e o registro biográfico. É vida, porque está colada aos acontecimentos e às experiências do cotidiano de um autor, ser vivente. $E$, também, é um espaço de morte, porque esse autor não fala isoladamente ou foi criado como uma mônada, mas antes dialoga com uma tradição, com as referências e os estilos de autores que já se foram, com os mortos da literatura; da arte, da dramaturgia ou até mesmo da sua própria linha parental.

Para Diana Klinger (2012, p. 54) o sujeito presente na escrita em primeira pessoa, que realiza esse procedimento de autoficção, permite que a ficção abra um espaço

2 Termo cunhado pelo próprio Alex Beigui. 
de exploração, excedendo assim, o próprio sujeito biográfico. Pouco interessa ou importa a relação do relato com uma "verdade" anterior a ele, no qual o texto sirva apenas de elemento para saciar a pulsão biográfica do escritor, mas antes o autor fala com a sua própria voz, porém, avisando ou deixando implícito ao leitor que não confie plenamente nele. A autoficção trabalhando como um procedimento de "envio, remissão sem origem, sem substrato transcendente". O que interessa na autoficção não é a relação do texto com a vida do autor, mas antes, a sua relação com o "mito do escritor".

Nesse aspecto, a autoficção atua como um dispositivo de criar mitos do escritor; tanto nas passagens em que se relatam e se observam as vivências do narrador, quanto nos momentos em que o autor introduz no relato textual uma referência ou referências a sua própria escrita, como por exemplo, a pergunta pelo lugar da fala; o que é ser escritor? Como acontece ou se desenvolve o processo da escrita? Quem diz eu? A matéria da autoficção não seria a biografia pura e simples, mas sim o mito do escritor. Um mito na perspectiva barthesiana: "não é uma mentira, nem uma confissão, é uma inflexão" (Barthes, 1989, p. 151).

Nesse entendimento a autoficção forja o "mito" do escritor, se mantendo num espaço desterritorializado entre a mentira e a confissão (onde o aspecto biográfico pode vir a ser tangenciado em diferentes níveis de intensidades), tendo a noção de relato como criação da subjetividade a partir da ambivalência a respeito de uma verdade prévia do texto. Esse desdobramento é o que permite pensar a autoficção como uma performance exclusiva do autor. Um texto de pulsão autoficcional parece implicar uma dramatização de si que exige um sujeito duplo (real e fictício/ ator/ personagem). Uma construção simultânea de ambos: autor e narrador ou escritor e personagem.

\section{Precisamos falar sobre Kane, Sarah Kane: um projeto existencial para a morte}

Pensar a escritura teatral contemporânea, sobretudo a obra de uma dramaturga como Sarah Kane é pensar exatamente nesse imbricamento, num fluxo contínuo e incessante que o autor se lança e por ele é lançado. E reconhecer que esse autor nunca está inteiro, única e solitariamente ali, mas antes da vazão a uma multiplicidade de vozes que ecoam no e do seu repertório composto por uma rede complexa que envolve biografia, história, referências e sentimentos. O texto nesse sentido, nunca é apenas "o texto", mas é sempre um emaranhado de micro tensões que vão além do jogo metonímico. É a ideia de pensar a performance como um campo amplo capaz de reunir abordagens comparadas e articular, a partir das analogias e das equivalências, os saberes distintos, de maneira completamente (des)hierarquizada. É pensar a escritura como um espaço guarda-chuva.

Para cada uma das escrituras de Kane, existe uma torrente de imagens poéticas que certamente brotam de uma experiência intelectual, existencial e da ordem dos sentimentos. Seus escritos não são portadores de sentidos e nem se propõe a, mas antes, portam presença. Nesse sentido, para Kane, escrever se torna uma ação subjetiva, cujas implicações envolvem e congregam um permanente conjunto de nego- 
ciações presenciais com o corpo político e estético, na imbricada tríade da criação artística: texto-corpo-mundo.

É nessa perspectiva que Beigui (2011) nos convida a pensar as performances da escrita como um modo de entender o contorno e os entornos da produção literária, não nos detendo na superficialidade da procura pelo sentido de um "contexto" da obra, mas nos interrogando sobre o que move a obra ao longo do tempo, levando em consideração, principalmente, os seus diferentes níveis de integração e desintegração do corpo-pensamento do artista e suas mídias.

O Teatro do Absurdo fez-se repleto de imagens poéticas porque seus dramaturgos sabiam que não podiam abandonar de vez a literatura, uma vez que ela é eminentemente discurso verbal. Ela problematiza e interpela sobre a sua condição, apostando em imagens sinestésicas ancoradas na presença e na experiência íntima de seus autores. Kane é uma artesã exímia nesse sentido de trabalhar com a literatura, na transubstanciação da palavra em imagem, na construção de uma escritura completamente visual, espaçada, lacunar e centrada em si.

Ainda segundo Beigui (2011, p. 31), é preciso investigar e estar atento a manifestação de um "projeto existencial" do autor, como sendo parte integrante de uma escrita performática ou da performance da escrita, uma vez que ele deve ser intrínseco à obra. O que ele nomeia como "projeto existencial" são os fundamentos das possíveis redes de presença, o sujeito como portador de vários sentidos que estão e são reorganizados na obra. Para ele, esse tipo de escrita requer um ato de intensificação e extensão de uma experiência ficcionalizada. Deve-se encarar a ficção como uma verdade que se faz presente no ato da leitura, da mesma maneira que todo o dado biográfico presente no texto seria a ficcionalização de uma realidade ou realidades dissolvidas, na emaranhada rede de subjetividade da escrita.

A obra de Kane está contaminada, de maneira indissociável, pelo seu "projeto existencial". Sua escritura é abastecida de seus dados biográficos, de suas memórias íntimas, vivências e experiências. A autora emaranha a sua vida de tal maneira ao longo do conjunto de sua obra que, por exemplo, na sua última escritura 4.48 Psychosis (2000), a personagem apresenta muitas semelhanças e características próprias à vida e a intimidade da autora; em relação aos dias de internamento, suas dosagens de medicação, seu tratamento psiquiátrico, suas ansiedades, frustrações e a tentativa de desnudar o seu texto-corpo-mente de maneira crua.

O fato é que essa escritura se torna uma das mais emblemáticas no corpus de obras kaneano, porque, além de relatar os diversos internamentos, os inúmeros tratamentos com medicamentos psicotrópicos, as várias frustrações amorosas e os dilemas de uma escritora em crise com a sua própria existência, coincide, exatamente, com o seu suicídio. Pensar na dramaturgia de Kane é pensar inevitavelmente num "projeto existencial para a morte". É levar em consideração que as suas cinco obras escritas para o palco ${ }^{3}$ - Blasted (1995), Phaedras's Love (1996), Cleansed (1998), Crave (1998) e 4.48 Psychosis (2000) - são todas obras que abordam, direta ou indiretamente, a morte, as diversas ideias e conceitos de morte, da finitude e o morrer. A

${ }^{3}$ Para fins didáticos e de fácil localização no texto, as obras citadas aqui estão todas reunidas em um volume único que contém os textos publicados de Kane em língua inglesa. Para maiores detalhes de referências consultar o final do artigo. 
morte não como um signo arquetípico, mas a morte como o único gozo absoluto e possível do homem.

Para Kane, a morte entrelaça-se na vida e na sexualidade de maneira indissociável. Mas a morte também está presente no diálogo que Kane mantém com a tradição, com a herança dramatúrgica e textual, no diálogo frenético com o passado, naquilo que Heiner Müller chama de "diálogo com os mortos" ". Observa-se em Blasted (1995), por exemplo, que boa parte das ações de escritura se passa em um quarto de hotel, um diálogo com Harold Pinter, dramaturgo o qual a autora admirava e quem tinha preferências por espaços privados, pequenos e domésticos, como o quarto ou a sala, para desenvolver suas histórias. Em Phaedras's Love (1996), Kane revisita as obras de Racine e Sêneca sobre Fedra, para criar a sua própria concepção, num jogo de referências, rastros e subversões das convenções.

Em Cleansed (1998), existe um diálogo com Artaud (e o seu teatro da crueldade e do encantamento das palavras) e com Beckett (na degradação da forma). Em Crave (1998), as referências parecem ser a lonesco, em sua estrutura de antiteatro e de humor mórbido. E por fim, 4.48 Psychosis (2000), quando finalmente parece ter esgotado a sua própria forma, é capaz de evocar, entre os longos fluxos verbais e os silêncios, todas as vozes do Teatro do Absurdo.

As referências à tradição, citadas aqui, são apenas exemplos generalizantes de primeira impressão, mas ao longo de cada escritura, existem referências diversas que vão da filosofia de Heidegger a aspectos da cultura local (aos amigos dramaturgos, críticos teatrais, familiares e até mesmo aos amores). Kane, parece ter aprendido com suas diversificadas fontes e leituras de autores anteriores a ela, que o segredo da escritura teatral está no diálogo com a tradição. Não no sentido de copiar, mas no sentido de estranhar, gerar ruído, arranhar o cânone e se inscrever dentro da própria tradição para encontrar uma zona propriamente sua.

A sensação ao ler cronologicamente as obras de Kane como um projeto para a morte é exatamente essa, de uma execução por etapas; alguém que inicia sua escrita num incessante diálogo com as suas referências, que consegue em momentos específicos ultrapassá-las, até desenvolver um tom solitário, eminentemente autoral e individualista em 4.48 Psychosis (2000), escritura que coincide e culmina com o fim da sua vida.

Kane deixa de evocar os mortos, para ela própria virar fantasma, ser evocada. Em vida, as relações com esses fantasmas da tradição pareciam estar chegando ao fim. Isso é dito em vários trechos de 4.48 Psychosis (2000). A autora escreve sobre o medo e a angústia de não conseguir criar, escrever e articular suas ideias. Sente que foi e está sendo prejudicada pelos medicamentos e que, a cada nova crise psicótica, aumentam cada vez mais as dosagens químicas. Por não conseguir viver sem dialogar com os seus fantasmas, por medo de ficar impossibilitada de se articular com eles, por pavor de perder a memória e "morrer", estando viva, não conseguindo mais contribuir com a dramaturgia e desenvolvendo a sua escrita, a autora escolhe se unir

${ }_{4}^{4}$ (Dialog mit Toten), metáfora mencionada por Müller durante uma conversa com Urs Jenny e Hellmuth Karasek em 1983. Diz respeito a um diálogo com a tradição dramaturgica e literária para a partir dela construir outras literaturas para agir no presente. Heiner Müller realizava esse procedimento particular por acreditar que nenhum texto é inédito e exclusivo, mas antes contém as infinidades de vozes que o perpassam. Para maiores informações sobre "Os fantasmas de Müller" em português, consultar a referência feita a Hans-Thies Lehmann, no final deste artigo. 
a eles, os fantasmas.

Essa poética do Tânatos, ou Tanatopoética que se estrutura na obra da dramaturga se fundamenta para além do diálogo com as referências, apresentando uma escrita sensível às questões da morte, repleta de imagens poéticas que tratam do indivíduo e de sua relação com a condição de mortalidade. A morte não como uma antagonista à vida ou a Eros, mas estando em igual protagonismo com a natureza humana, sem dissociação ou maniqueísmos. A morte como uma característica performativa per se, essencial e indissociável do teatro.

Nessa perspectiva, consideremos a escritura de 4:48 Psychosis (2000) como sendo o espaço por excelência da manifestação do projeto existencial de sua autora; o lugar no qual a escrita de si, performativa e performática, se revela repleta de potências que se orientam também a forjar o mito de Kane, a autora que parece anunciar o seu próprio suicídio. A instauração de um lugar fronteiriço que num dado momento transborda e mortalmente atinge a sua criadora. Como uma espécie de espelho encantado que realiza um movimento duplo e controverso: captura e liberta ao mesmo tempo. Ele aprisiona sua autora num mito (terá mesmo acontecido dessa maneira? É Kane quem nos fala? De quem é a voz? O que quer dizer especificamente isso?) e a liberta para a condição de fantasma a ser evocado, um espectro caro a dramaturgia ocidental do século XXI.

\section{A personagem Golem: entre o duplo e a fantasmagoria}

Em 4.48 Psychosis (2000), o fato de a personagem parecer direcionar sua fala para o leitor, falando direta e abertamente, estabelece um jogo esquizofrênico que hora remete ao "eu" da personagem em completa derrisão, hora ao "eu" de Kane sujeito-escritora. Fato esse que tende a confundir os leitores, em seus níveis iniciais de contato com a escritura e com a vida da autora. A personagem que não tem um nome e possui devires ao invés de uma identidade, parece ser dotada dessa "singularidade situada em um nível elevado", não pode ser nomeada por impotência do próprio ato de nomear. Nomear é, também, a tentativa de limitar, apreender ou docilizar.

Observou-se nisso, portanto, que a personagem opera num determinado modo e grau de individuação sem sujeito; de uma individuação impessoal, especificamente marcada e que se cartografa pela capacidade de produzir afetos, potências e intensidades. Quando se analisa ou pensa nas personagens de Kane, e isso se torna mais sintomático na personagem sem nome de 4.48 Psychosis (2000), vem-se o entendimento da lenda judaica místico-cabalística da figura do Golem, descrita em Gershon Scholem (2006, p. 190-191):

Depois de pronunciar certas preces e observar certos dias de jejum, os judeus poloneses fazem a figura de um homem, de barro ou de lodo, que deve tomar vida ao ser pronunciado sobre ele o miraculoso Schemhamphoras (o nome de Deus). Ele não pode falar, mas entende razoavelmente bem o que é dito ou ordenado. Chamam-no de golem e empregam-no para executar toda espécie de serviços domésticos. Mas jamais deve deixar a casa. Sobre sua fronte está escrita a palavra emet (verdade); a cada dia ele ganha peso e fica um pouco maior e mais forte do que todos os outros dentro da casa, independentemente do quão pequeno era no começo. De medo dele, apagam, por isso, a primeira letra, de modo a restar ape- 
nas met (ele está morto), depois que ele cai por terra e se transforma em barro [...].

Aos moldes da criação do golem, o seu escultor-criador, lança sobre ela pensamentos e se entrega a uma preparação criadora que atuam com o efeito da prece $e$ do jejum em silêncio. A matéria que compõe a personagem, em semelhança com o barro ou o lodo que vem da terra, sustenta os fundamentos de um mundo material e abriga os micro-organismos da vida: é a escrita, a tessitura e o jogo das palavras que estruturam a personagem. Ainda em fase de amálgama, combinadas e postas em jogo, as palavras criam uma singularidade individual. Diante dessa singularidade, 0 autor-escritor lança sobre ela o miraculoso Schemhamphoras: o seu encantamento próprio, um mistério íntimo e particular, os devires. Eis, então, a forma.

Chamam-no de golem. Dizem: é uma personagem! Ele não pode falar, porque não sabe falar, mas entende razoavelmente bem o que é dito ou ordenado. Antes alguém a faz falar, uma vez que ela não tem voz própria, mas é a voz de um outro. Assim, a personagem é empregada para executar toda a espécie de serviço dentro da escritura. É ela, a agente visível e operacional do jogo estabelecido dentro da estrutura. Porém, lhe é dado uma regra: permanecer no limite (desenvolver a sua potência). Sobre a sua fronte está escrita a palavra emet. A verdade, e a linha de fuga da escritura pertencem ou são liberadas, por ela.

A cada dia ele ganha peso e fica um pouco maior e mais forte do que os outros dentro da casa, independentemente do quão pequeno era no começo. Como uma forma e um desejo de transbordamento, começa a partir das experimentações e vai tendo o aumento de sua potência para além da forma e do molde. A ela só cabe fugir e distanciar-se, deixando rastros e borrões do que fora outrora.

De medo dele, apagam, por isso, a primeira letra, de modo a restar apenas met (ele está morto). O grau de potência que a personagem consegue atingir passa a afetar as estruturas, que se transformam e se transbordam, subvertendo e desencadeando um colapso na ordem da linguagem teatral e no modo de funcionamento de seus múltiplos sistemas.

Então, a casa (a dramaturgia) que existia com estruturas muito bem definidas e reconhecidas como sendo um lar, podendo ser facilmente reconhecida e apreendida de qualquer ponto, passa a ser ruínas, desterritorialização. O seu terreno torna-se um campo aberto de possibilidades que lhe fogem constantemente, sem que haja uma abordagem efetiva e completa, capaz de apreender ou nomear o instante que se tornou.

A única solução possível: a morte. Dessa maneira, surge a sentença: a personagem está morta. Falida, findada, perecida ou em decomposição. Uma infinidade de sinônimos para a instauração de um duplo, que parece funcionar de maneira generalizante, desse modo: se a noção e o desenho da personagem, como conhecidos anteriormente, estão mortos, e com isso, a partir da noção materialista do morrer, diz que se extinguiram; retira-se o nome "a personagem". Ou, assumindo uma perspectiva transcendental e metafísica do morrer, diz-se que a noção de personagem transbordou, no sentido de se libertar de um único corpo estrutural, precipitando-se em uma teia invisível de afetos, potências e sensibilidades, suspensas em um lugar que não se consegue e não se pretende nomear. 
Porém, uma coisa é certa: depois que ele cai por terra e se transforma em barro, não importa o sentido que se atribua à morte da personagem: se desaparecimento ou potência, o que interessa é que ela volta às origens de sua criação, à ordem da palavra e à materialidade de sua forma primeira, o artifício. Segundo Scholem (2006), a investigação do golem como um "homem criado por artes mágicas" nos remete diretamente a:

Certas ideias judaicas referentes a Adão, o primeiro homem. Pois, obviamente, um homem que se dispõe a criar um golem está competindo com a criação de Adão por Deus; num tal ato, a força criadora do homem entra num certo relacionamento, seja de emulação, seja de antagonismo, com o poder criador de Deus (Scholem, 2006, p.191).

Deturpando e torcendo o sentido da expressão "homem criado por artes mágicas" para o campo de análise desse artigo, têm-se os seguintes paralelos: homem/ personagem e artes mágicas/potência da criação. Nesse caso, a personagem concebida por Kane, a partir das linhas de fuga e das "potências de criação" postas em movimento na escritura, se configura como um golem. Se a personagem da escritura kaneana se constitui dessa maneira, existe uma relação primordial com a questão da abstração e do apagamento por completo do nome próprio da personagem, que some em 4.48 Psychosis (2000).

Por meio de um ato apropriativo, invisto nessa relação mistico-criacionista Deus e Adão - Criador/Criatura, para desenvolver e inscrever o meu raciocínio da seguinte maneira: Kane mantém uma dialógica com a personagem golem (Kane/golem), em sua última escritura, que alterna entre o distanciamento e a emulação. O distanciamento ocorre de maneira que a personagem transborda a escritura e a própria moldura da estrutura, não pertencendo mais a Kane, mas às forças constituintes de uma "criação coletiva", nos moldes do "imaginário coletivo" que passa a fazer parte das operações poéticas nas escrituras do início do século XXI. A emulação está associada à persona de sua autora, de maneira a induzir uma relação de ordem eminentemente autobiográfica na obra.

A única personagem visível de 4.48 Psychosis (2000) não tem nome. Não o diz, não o menciona, e também não o procura recuperar. Formal e estilisticamente desenvolvida, sua escritura parece ser um aprimoramento, e consequentemente o fim, da identidade fictícia e da própria ideia de personagem que se enraizou na literatura dramática do teatro ocidental. O leitor é apresentado e conduzido por uma persona que não se apresenta, mas possui a fala e exerce o poder do discurso.

Existe uma verdadeira torrente verbal: jogos com palavras e referências particulares de modo a criar uma criptografia que parece nos levar ao espaço da mente dessa persona, de modo a sermos afectados diretamente pelo seu devir pensamento. Um devir que não parece ser direcionado a alguém, mas que possui uma potência de afectação que atinge a todos.

A fala de quem detém o poder de discurso, nessa escritura, está sempre na ordem moderna do "eu". É justamente para dar conta dessa condição de indivíduo, e da noção freudiana de ego, que o texto traz referências a termos da psiquiatria e da psicanálise, revelando o espaço que se alterna na obra entre clínica e quarto-intimi- 
dade do "eu" narrador. Aos poucos, o leitor vai entendendo que outras personagens "existem", e são evocadas e organizadas pelo discurso clínico característico como pacientes e médicos de uma instituição psiquiátrica.

Em determinados momentos da escritura, existe o tom limítrofe entre o biográfico e o fictício, que parece direcionar o leitor para o universo íntimo e pessoal de Kane. Existem informações que sugerem uma série de dados íntimos sobre os internamentos, a aparência física, a autoestima e as frustrações amorosas particulares. Essas revelações aparecem como se fossem rastros desencadeados pela personagem que se juntam a outros detalhes sobre educação familiar, fama, reconhecimento, crise, nomes de medicamentos, suas dosagens e seus medos.

O espaço parece sempre minimalista, há algumas indicações que sugerem um quarto, mas a voz do texto nos leva a outros espaços que estão, e convivem, para além de um simples quarto. As indicações sobre o corpo não sugerem grandes movimentações físicas, nem tampouco existe uma evocação a ele enquanto espaço de liberdade que precise romper e sair desse quarto.

O corpo se assemelha à categoria de objeto, ocupando na escritura o mesmo lugar que o espaço físico descrito nas falas. É um corpo desprovido, ausente de nome. É um "corpo-texto", parafraseando Beigui (2011). A voz que fala não quer sair dessa situação, não faz grandes menções a um passado e nem projeta um futuro. Ela vive o agora, e no instante em que fala. Como afirma a voz da escritura, ela deseja se matar às 4.48 , hora em potencial dos suicidas, e conclui a escritura pedindo para abrirem as cortinas.

Para Anne Ubersfeld (2010, p. 87) toda análise concreta que se faça do discurso teatral tem que levar em consideração a questão da dupla enunciação: "a personagem fala em seu nome, enquanto personagem, mas fala porque o autor a faz falar, intima-a a falar e a dizer determinadas palavras". Nessa perspectiva, a fala de uma personagem será sempre da ordem do autor/escritor, que a faz falar, para orquestrar e articular um discurso construído que primeiramente simula a fala, e em seguida, trata do pensamento e da estrutura de sentimento na qual está inserido o universo do autor/escritor. Ou ainda:

[...] o que a representação teatral exprime, sua mensagem própria, não é tanto o discurso das personagens, mas as condições de exercício desse discurso [...] o teatro diz menos uma fala e mais o modo como se pode ou não se pode falar. Todas as camadas textuais (didascálias + elementos didascálicos no diálogo) que definem uma situação de comunicação das personagens, determinando as condições de enunciação de seus discursos, têm como função não somente modificar o sentido das mensagens-diálogos, mas constituir mensagens autônomas, capazes de exprimir a relação entre os discursos, e as possibilidades ou impossibilidades das relações interpessoais (Ubersfeld, 2010, p.161).

Às vezes o ato de realizar uma simples análise textual foge dos domínios do leitor ou do ator, se tornando quase uma impossibilidade de compreensão do todo da personagem, devido às condições de exercício do(s) discurso(s) contido(s) no corpo da escritura. Algumas dessas condições se dão de maneira bastante fragmentadas e hermeticamente particulares. Ao fazer com que apreendamos os rastros dela, a cada leitura ou montagem teremos outras possibilidades infinitas de rastros, o que poten- 
cializa e transforma o alcance não da personagem, mas do discurso de seu autor/ escritor.

A mensagem que a personagem golem, ou o que a "voz" dela nos diz em 4.48 Psychosis (2000), está muito mais na relação entre a personagem e a clínica psiquiátrica; a personagem e a indústria farmacêutica; a personagem e a sua mente; ou a personagem e o seu quarto solitário da clínica, do que no seu próprio discurso. A questão da mensagem nas obras contemporâneas parece localizar-se mais nas condições de "exercício" ou de "não-exercício" de uma fala, do que no todo do discurso, como bem coloca Ubersfeld (2010).

A questão é deslocada para a condição de agenciamento do discurso: o que se pode dizer quando the fora tirado ou apagado o nome? Como proceder quando não é possível se reconhecer dentro de uma identidade? Que nome ou a que nomes procurar quando planeja se matar? O que se diz dentro da própria mente? Ou ainda, o que se diz ao encontrar-se num quarto solitário de uma clínica psiquiátrica, após haver tomado um coquetel de medicamentos tranquilizantes?

Semelhante à atitude tomada em Cleansed (1998) Kane não tem nada a responder, nada a indicar além da própria afirmação do nada. Como Beckett, já havia descoberto anos antes: não há nada a se fazer, nada a esperar. Essa parece ser a mesma resposta de Kane, não há nada antes do nome e nem haverá nada após ele. Mas parafraseando Derrida (1995), é necessário salvar o nome. Só a linguagem, mesmo esfacelada, em ruínas no mundo de absurdos, é que parece sobreviver.

\section{Considerações finais}

O grande conhecimento teórico e técnico de Kane sobre a tradição da linguagem teatral, junto com a sua admiração e inclinação por autores considerados de linhagem absurdista e em oposição à estética realista foram de extrema importância para o desenvolvimento de seus trabalhos em direção à criação de uma "nova" estética que correspondesse, inicialmente, aos seus anseios e em seguida, que fossem capazes de apresentar as angústias da época e suprir às novas necessidades da cena que se desenhavam no período.

Nesse sentido, o desmonte, a fragmentação, o jogo e a provocação da e na linguagem teatral é o resultado de seu constante e frenético diálogo com os mortos da tradição literária e dramatúrgica e com outras referências culturais na busca por novos caminhos e um espaço para a inscrição de sua obra prenhe de possibilidades para a literatura e para o teatro do período. Dito isto, é importante destacar que Kane não esteve presa ou não se declarou pertencer a nenhuma filiação estética. A autora passou sua curta carreira se esquivando e se livrando de rótulos ou de nomeações. Portanto, é possível localizarmos e até identificarmos as referências absurdistas da autora concluindo que as mesmas são cruciais ao desenvolvimento de sua obra, ou como prefere Kane no trajeto da "cleptomania literária" de sua estética.

Ao longo dos curtos anos em que produziu profissionalmente para o teatro, após o grande escândalo midiático e profissional que foi e escrita e apresentação de sua primeira obra para o teatro, Blasted (1995), Kane foi percebendo a necessidade de rever, revisitar e redimensionar nas suas escrituras a multiplicidade dos seus pon- 
tos de vista sobre um mesmo assunto, bem como a diversidade e o arsenal das referências que lhe moviam enquanto artista e ser humano, a autora pretendia tanto ser compreendida quanto ser lida de uma maneira íntima, quase completa. A partir desse movimento de exposição de si em suas escrituras, podemos concluir que a autora não conseguia se separar de sua obra.

Kane apresentava a impossibilidade de se abandonar e se fragmentar enquanto artista, sua obra era a ficcionalização e a performatização da sua vida e a sua vida era, por conseguinte, preenchida pelos desdobramentos e repercussão de sua obra. 0 maior exemplo dessa busca e investimento incessante numa escritura que portasse totalmente a sua voz, presença e pensamento é o desenvolvimento da sua obra na produção daquilo que nomeio como sendo a "trilogia da perda da identidade", composta por: Cleansed (1998), Crave (1998) e 4.48 Psychosis (2000).

Essas três escrituras estão ligadas e costuradas por um fio condutor e central que é o fio da morte ou a morte como um projeto existencial. A morte da personagem em favor e em detrimento da personagem golem que se faz portadora de um discurso polifônico, referencial e biográfico de sua autora. A medida que Kane vai progredindo nesse intento as suas personagens vão se desfazendo parcialmente; primeiro perdem os nomes próprios e ganham nomeações sinonímicas em Cleansed (1998); depois são indicadas apenas por uma única letra e abrindo mão do seu direito a uma voz única que lhe identifique, como em Crave (1998), e por fim, desaparecem em nome, em indicação e em quantidade, a personagem se torna um golem sem nome, agindo como um dispositivo de duplo e de fantasmagoria de sua autora no que diz respeito ao relato e apresentação de seus pensamentos íntimos e confessionais (a impossibilidade do amor e o jogo com o misticismo religioso); do seu universo biográfico em vias com a clínica médica e com a medicamentalização excessiva da vida; suas questões em relação à estética de sua obra e seus sistemas operativos, em 4.48 Psychosis (2000).

Se a morte não se mostra em Kane como um polo de oposição a vida, mas antes está essencial e indissociavelmente unida a ela, a obra certamente acaba portando as referências da morte de sua autora. Essa escritura traz em seu corpo ligações, confissões e citações numa trama cuja linha de fuga essencial é a maturação, o desenvolvimento e a conclusão do ato performativo e suicida em curso, e exposto verbalmente, ao leitor/ espectador ao longo de toda a escritura.

\section{Referências}

BARTHES, Roland. O Grau Zero da Escrita. São Paulo: Martins Fontes, 2004.

Mitologias. Rio de Janeiro: Bertrand Brasil, 1989.

BEIGUI, Alex. Performances da Escrita. Aletria: Revista de Estudos da Literatura, Minas Gerais, V. 21, n 01, 2011, p.27-36, jan.- abril 2011.

DELEUZE, Gilles. (1968). Lógica do Sentido. São Paulo: Perspectiva, 1998. 
DERRIDA, Jacques. Salvo o Nome. Campinas: Papirus, 1995. Gramatologia. São Paulo: Perspectiva, 1973.

UBERSFELD, Anne. Para Ler o Teatro. São Paulo: Perspectiva, 2010.

KLINGER, Diana I. Auto ficção e performance. In. Escritas de Si, Escritas do Outro: o retorno do autor e a virada etnográfica. 2006. 204f. Tese. (Doutorado em Letras) - Instituto de Letras da UERJ. Universidade do Estado do Rio de Janeiro. Rio de Janeiro-RJ.p.52-61.

KANE, Sarah. Complete Plays. Londres - UK: Methuen Drama, 2001.

LEHMANN, Hans-Thies. Estudos sobre Heiner Müller. In: Escritura Política no Texto Teatral. São Paulo: Perspectiva, 2009. p.302-405.

SCHOLEM, Gershom. A cabala e seu simbolismo. São Paulo: Perspectiva, 2006.

Recebido em: 30/04/2017 Aprovado em: 21/06/2017 